\title{
Bronchoalveolar lavage in farmers' lung disease: diagnostic and physiological significance
}

\author{
Y CORMIER, J BÉLANGER, P LEBLANC, AND M LAVIOLETTE \\ From the Centre de Pneumologie, Hôpital Laval, Ste-Foy, PQ, Canada GIV 4 G5
}

ABSTRACT A group of 92 farmers had clinical evaluation, pulmonary function tests, and bronchoalveolar lavage (BAL). There were 12 patients with acute farmers' lung disease (FLD) (group 1) and 37 farmers who had had acute FLD, of whom 22 were still on their farm (group 2) and 15 had ceased contact (group 3); others were normal dairy farmers, 23 serology positive to Micropolyspora faeni (group 4), 20 serology negative (group 5), and 42 normal controls (group 6). Of the 134 subjects, 59 had an increase in alveolar lymphocytes $(>22 \%$ lymphocytes in BAL) (12 in group 1,19 in group 2 , six in group 3, 14 in group 4, five in group 5, and three in group 6). Within each group there was no correlation between BAL lymphocytes (\% and absolute number) and most pulmonary function tests. It is concluded that although an increase in BAL lymphocytes is always seen in acute FLD it may also be seen in the absence of clinically evident disease and that BAL lymphocytosis does not correlate with physiological changes in FLD.

Bronchoalveolar lavage (BAL) has recently gained widespread popularity both as a research tool and in the clinical evaluation of interstitial lung disease. ${ }^{1-3}$ Different patterns of cellular alterations have been well described. Patients with extrinsic allergic alveolitis (EAA) and sarcoidosis characteristically have an increased percentage of lymphocytes in their BAL, whereas in idiopathic interstitial fibrosis an increase in polymorphonuclear cells is usually seen. In sarcoidosis it has been suggested that BAL could be useful, not only to support the diagnosis but also to predict the outcome. ${ }^{4}$ Patients with sarcoidosis with more than $28 \%$ T-lymphocytes have a less favourable prognosis than those with fewer cells. ${ }^{5}$ This technique is therefore suggested as a follow up tool for different interstitial processes.

It is well accepted that patients with EAA have a large number of lymphocytes in their BAL. ${ }^{26-8} \mathrm{We}$ have previously described that an abnormal increase in the number of BAL lymphocytes are also often seen in asymptomatic dairy farmers ${ }^{9}$ and in subjects with previous farmers' lung disease (FLD). ${ }^{10}$ The exact role and clinical significance of these bronchoalveolar lymphocytes is not known. The purpose of this study was to evaluate how well the results of BAL correlate with the physiological alterations found in FLD.

Accepted 9 September 1985

\section{Subjects and methods}

Ninety two farmers from rural communities surrounding Quebec city and 42 normal volunteers were included in the study. The farmers (13 women, 79 men) had a mean age of $43.0 \pm 11.8$ years. They comprised five clinical groups:

Group 1-Twelve consecutive subjects with acute farmers' lung disease.

Group 2-Twenty two subjects with previous farmers' lung disease and still in daily contact with hay.

Group 3-Fifteen subjects with previous disease as group 2 but who had ceased all contact.

Group 4-Twenty three normal dairy farmers with positive serum precipitins to Micropolyspora faeni by double diffusion. ${ }^{11}$

Group 5-Twenty normal, serology negative farmers.

The 12 subjects in group 1 were acutely ill at the time of study - that is, they had had a recent onset (under one month) of shortness of breath, malaise, fever, and dry cough and had consulted for the persistence of these symptoms. All were studied within nine days of their last contact. There were no current cigarette smokers in this group. The diagnosis of FLD was also based on physical examination, chest radiographs, serum precipitin analysis, and pulmonary function tests. ${ }^{12}$ Biopsies (transbronchial, trephine, or open) were not routinely used but reserved for subjects where diagnostic doubts persisted after the initial 
evaluation ( 23 of the 49 subjects with past or present FLD (groups 1 to 3 )).

Subjects in groups 2 and 3 had received their diagnosis between one and 10 years before the study and were recruited from among our eligible ex-FLD patients. No subject had complained of symptoms, such as evening chills, malaise, dyspnoea, or loss of weight during the year before the study and only one had taken corticosteroids during the past year. He had had a progressively tapered dose of prednisolone which had been terminated three months before the study. There were two smokers in each of groups 2 and 3. Subjects in groups 4 and 5 were taken from our epidemiological study of 888 dairy farmers ${ }^{13}$ and selected on the basis of their precipitin status. Group 4 were serology positive to Micropolyspora faeni; group 5 subjects were seronegative and matched with subjects of group 4 for age, size of farm, and contact. All the subjects in these two groups were nonsmokers. Subjects in groups 2 to 5 were studied in the winter months; those of groups 2, 4, and 5 did their morning farm chores the day of their study. Barn exposure was similar for subjects of groups 2,4 , and 5 . For group 2 subjects, two spent less than one hour a day in the barn, five between one and three hours, 13 between three and six hours, and six more than six hours. For subjects in group 4, two spent between one and three hours, 12 between three and six hours, and nine more than six hours. Group 5 subjects were matched with subjects of group 4 for this variable and therefore had the same exposure.

Studies consisted of a clinical evaluation, pulmonary function tests, and bronchoalveolar lavage. Pulmonary function tests included forced expiratory flows for all subjects, diffusing capacity (DLCO) for 91 subjects, and lung volumes (plethysmography) in 75 subjects. Arterial oxygen tension $\left(\mathrm{PaO}_{2}\right)$ was measured before BAL in five subjects in group 1. The results of the pulmonary function tests are reported as a percentage of the predicted results, except for the forced expired volume in one second to forced vital capacity ratio $\left(\mathrm{FEV}_{1} / \mathrm{FVC}\right)$, which is given as such.

A sixth group of 42 subjects, for the most part university students or workers at the hospital, served as normal controls. ${ }^{14}$ There were 22 men and 20 women (mean age 24.8 years, range 19-41); 38 had never smoked and four were ex-smokers who had not smoked for at least two years.

Informed consent was obtained from all subjects. BAL was performed under local anaesthesia using a flexible bronchoscope. All lavages were done in the right middle lobe with $300 \mathrm{ml}$ of physiological saline (ten $30 \mathrm{ml}$ aliquots) as previously described. ${ }^{69}$ Lavage fluid was kept on ice until centrifuged at $500 \mathrm{~g}$ for 10 minutes at $4^{\circ} \mathrm{C}$. The total cell count was measured on a haemocytometer, with the differential determined on Wright-Giemsa and non-specific esterase stained cytocentrifuged preparations (Cytospin, Shandon, Sewickley, PA). Six hundred or more cells were counted. We defined an alveolitis as a percentage of BAL lymphocytes greater than 22 . This figure was calculated from the one tailed $95 \%$ confidence interval of the controls' mean.

For the statistical analysis of the number of cells, percentage of lymphocytes, and DLCO the KruskalWallis test and Tukey's test with Dunn's standard of error were used. $^{15}$ For the other variables the Student-Newman-Keuls test for multiple comparisons between groups was used. Correlations between variables were assessed by Spearman's rank correlation.

\section{Results}

Serum precipitins to MF were, by definition, negative for group 5 subjects and positive in group 4 (with titres ranging from a $1 / 8$ dilution to a twofold concentration). Precipitins were detected in seven subjects in group 1, 14 in group 2, and three in group 3. Table 1 shows the clinical characteristics and the results of the pulmonary function tests. Statistical analysis of these data showed that groups 1 and 2 subjects had lower DLCO than groups 4, 5, and 6 (p $<0.001$ except between groups 2 and 6 where $p<0.05$ ). DLCO was also significantly lower in group 3 than in group 5 ( $\mathrm{p}<0.02)$; therefore subjects with current or ex-FLD had lower DLCO than subjects who had no previous clinical evidence of the disease. Total lung capacity results were higher in groups 4 and $6(p<0.05)$ and FVC values were lower in groups 1 and $2(p<0.05)$. Variance analysis did not separate the six groups in respect of $\mathrm{FEV}_{1} / \mathrm{FVC}$, which was similar for all groups.

The total number of cells recovered in BAL (table 2) was smaller in group 6 than in all the other groups ( $p<0.001$ with groups $1,2,4,<0.002$ with group 3, and $<0.02$ with group 5). Group 5 subjects also had fewer cells than group 1; other comparisons were not significantly different. The percentage of lymphocytes was lower in group 6 than in groups $1-4$ (p $<0.001$ group 1, 2, 4 and $<0.02$ group 3). Group 5 subjects had a smaller percentage of lymphocyte than groups 1 and $2(p<0.001)$, and group 3 subjects had fewer lymphocytes than those in group 1 ( $p<$ $0.05)$. All subjects of group 1 had more than $22 \%$ of lymphocytes in their BAL (fig la). Most group 2 subjects (19/22) also had a high percentage of lympho- 0 cytes in their BAL. Lymphocytes were also increased in almost half (19/43) of the farmers of groups 4 and 5. As may be seen in fig 1 , all four smokers had a low percentage of BAL lymphocytes. Three control subjects had more than $22 \%$ of lymphocytes in their 
Table 1 Clinical and physiological characteristics of the study population

\begin{tabular}{|c|c|c|c|c|c|c|c|c|}
\hline Group & & No & $\boldsymbol{M} / \boldsymbol{F}$ & Age (years) & $T L C^{*}$ & $F V C^{*}$ & $F E V_{1} / F V C$ & $D L C O^{*}$ \\
\hline$\overline{1}$ & Acute FLD & 12 & $10 / 2$ & \multirow{6}{*}{$\begin{array}{l}43 \cdot 4 \\
\pm 11 \cdot 4 \\
47.9 \\
\pm 11 \cdot 5 \\
42 \cdot 0 \\
\pm 9 \cdot 0 \\
40 \cdot 6 \\
\pm 12 \cdot 3 \\
40.8 \\
\pm 13 \cdot 0 \\
24 \cdot 8 \\
\pm 5.0\end{array}$} & \multirow{6}{*}{$\begin{array}{l}87.7 \\
\pm 14.8 \\
91.2 \\
\pm 14.5 \\
91.5 \\
\pm 11.0 \\
109.1 \\
\pm 10.0 \\
99.4 \\
\pm 8.4 \\
100 \cdot 3 \\
\pm 11.8\end{array}$} & \multirow{6}{*}{$\begin{array}{l}72 \cdot 8 \\
\pm 11 \cdot 6 \\
81 \cdot 0 \\
\pm 14 \cdot 5 \\
89 \cdot 5 \\
\pm 14 \cdot 7 \\
99 \cdot 0 \\
\pm 13 \cdot 3 \\
98 \cdot 3 \\
\pm 11 \cdot 3 \\
98 \cdot 3 \\
\pm 11.9\end{array}$} & \multirow{6}{*}{$\begin{array}{l}78 \cdot 4 \\
\pm 4 \cdot 0 \\
76 \cdot 7 \\
\pm 11 \cdot 3 \\
78 \cdot 4 \\
\pm 6 \cdot 0 \\
78.0 \\
\pm 5 \cdot 9 \\
78 \cdot 6 \\
\pm 5 \cdot 6 \\
82 \cdot 5 \\
\pm 5 \cdot 4\end{array}$} & \multirow{6}{*}{$\begin{array}{l}60 \cdot 9 \\
\pm 17 \cdot 7 \\
73 \cdot 5 \\
\pm 21 \cdot 8 \\
85 \cdot 3 \\
\pm 22 \cdot 2 \\
108 \cdot 3 \\
\pm 30 \cdot 2 \\
109 \cdot 5 \\
\pm 18 \cdot 1 \\
94 \cdot 1 \\
\pm 12 \cdot 6\end{array}$} \\
\hline 2 & Ex-FLD on farm & 22 & $17 / 5$ & & & & & \\
\hline 3 & Ex-FLD no contact & 15 & $14 / 1$ & & & & & \\
\hline 4 & \multirow{3}{*}{$\begin{array}{l}\text { Normal farmers } \\
\text { seropositive } \\
\text { Normal farmers } \\
\text { seronegative } \\
\text { Controls }\end{array}$} & 23 & $20 / 3$ & & & & & \\
\hline 5 & & 20 & $18 / 2$ & & & & & \\
\hline 6 & & 42 & $22 / 20$ & & & & & \\
\hline
\end{tabular}

All values are mean + SD.

* Data expressed as $\%$ of predicted.

TLC = Total lung capacity.

FVC $=$ Forced vital capacity

FEV $_{1}=$ Forced expired volume in one second.

DLCO = Carbon monoxide diffusing capacity.

FLD = Farmers' lung disease.

Table 2 Results of bronchoalveolar lavage

\begin{tabular}{|c|c|c|c|c|c|}
\hline Group & $\begin{array}{l}\text { Volume recovered } \\
\text { (\% of infused })\end{array}$ & $\begin{array}{l}\text { Total cell count } \\
\times 10^{6}\end{array}$ & $\begin{array}{l}\text { Macrophages } \\
(\%)\end{array}$ & $\begin{array}{l}\text { Lymphocytes } \\
(\%)\end{array}$ & $\begin{array}{l}\text { Neutrophils } \\
(\%)\end{array}$ \\
\hline $\begin{array}{l} \\
2 \\
3 \\
4 \\
5 \\
6\end{array}$ & $\begin{array}{l}62 \cdot 8 \\
\pm 15 \cdot 0 \\
61 \cdot 2 \\
\pm 10 \cdot 6 \\
67 \cdot 5 \\
\pm 8.9 \\
67 \cdot 6 \\
\pm 9.6 \\
68 \cdot 7 \\
\pm 7 \cdot 7 \\
69 \cdot 0 \\
\pm 7 \cdot 3\end{array}$ & $\begin{array}{l}93 \cdot 1 \\
\pm 55.7 \\
51 \cdot 7 \\
\pm 33.0 \\
37.2 \\
\pm 34.3 \\
35.2 \\
\pm 25.9 \\
24.8 \\
\pm 16.0 \\
10.9 \\
\pm 6.2\end{array}$ & $\begin{array}{l}23 \cdot 3 \\
\pm 9 \cdot 3 \\
46.9 \\
\pm 22.1 \\
71 \cdot 7 \\
\pm 18 \cdot 1 \\
65.8 \\
\pm 21 \cdot 0 \\
81.4 \\
\pm 12.9 \\
88.6 \\
\pm 7.9\end{array}$ & $\begin{array}{l}66 \cdot 2 \\
\pm 18 \cdot 3 \\
49.9 \\
\pm 22 \cdot 7 \\
26 \cdot 1 \\
\pm 18 \cdot 5 \\
31 \cdot 2 \\
\pm 21 \cdot 6 \\
15.6 \\
\pm 10 \cdot 8 \\
9.6 \\
\pm 7 \cdot 7\end{array}$ & $\begin{array}{l}10 \cdot 1 \\
\pm 13 \cdot 9 \\
2 \cdot 8 \\
\pm 3 \cdot 3 \\
1 \cdot 7 \\
\pm 1 \cdot 8 \\
2 \cdot 2 \\
\pm 2 \cdot 1 \\
3 \cdot 0 \\
\pm 3 \cdot 1 \\
1 \cdot 7 \\
\pm 1 \cdot 2\end{array}$ \\
\hline
\end{tabular}

BAL; all were asymptomatic and only one had a subnormal FVC ( $73 \%$ of predicted) with no other deficits. In fig 2 we show that within groups there were no correlations between percentage of BAL lymphocytes and DLCO. For the other pulmonary functions

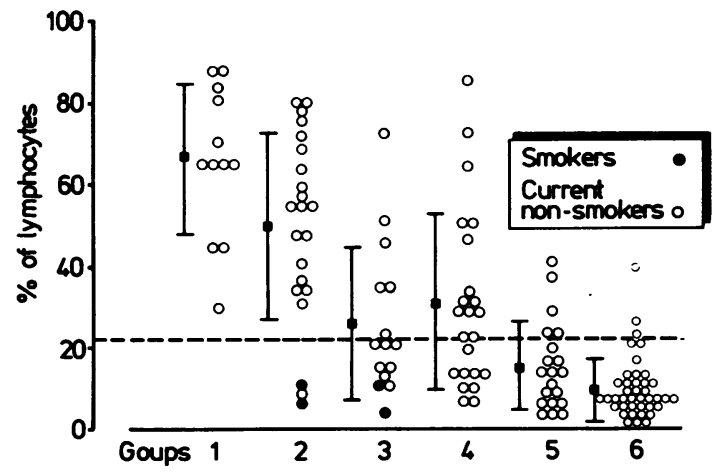

Fig 1 Individual values and mean $\pm S D$ for percentage of lymphocytes in bronchoalveolar lavage for six groups of subjects. Dotted line shows threshold for normals values as defined in text ( $>22 \%$ of lymphocytes). a significant positive correlation was seen between the percentage of lymphocytes and total lung capacity in group $5\left(r_{s}=0.54 ; p=0.03\right)$. For the FVC a significant negative correlation between BAL lymphocytes was seen only in group $3\left(r_{s}=-0.58\right.$; $\mathrm{p}=0.02$ ).

\section{Discussion}

Our data show that BAL is a sensitive tool in diagnosing FLD. All 12 subjects with acute disease had an increased number and percentage of lymphocytes in their BAL fluid. A normal lavage would therefore rule out an acute extrinsic allergic alveolitis. In this respect, BAL may be considered superior to precipitin analysis where, despite multiple antigen testing, a significant number of sera have no detectable precipitating antibodies. ${ }^{1617}$ Unfortunately, although BAL may be $100 \%$ sensitive an increase in lymphocytes is not present only in acute disease. Several clinically normal dairy farmers also have a large percentage of lymphocytes in their BAL; this is also seen in farmers who had previously had FLD.

We can only speculate on the meaning of increased 

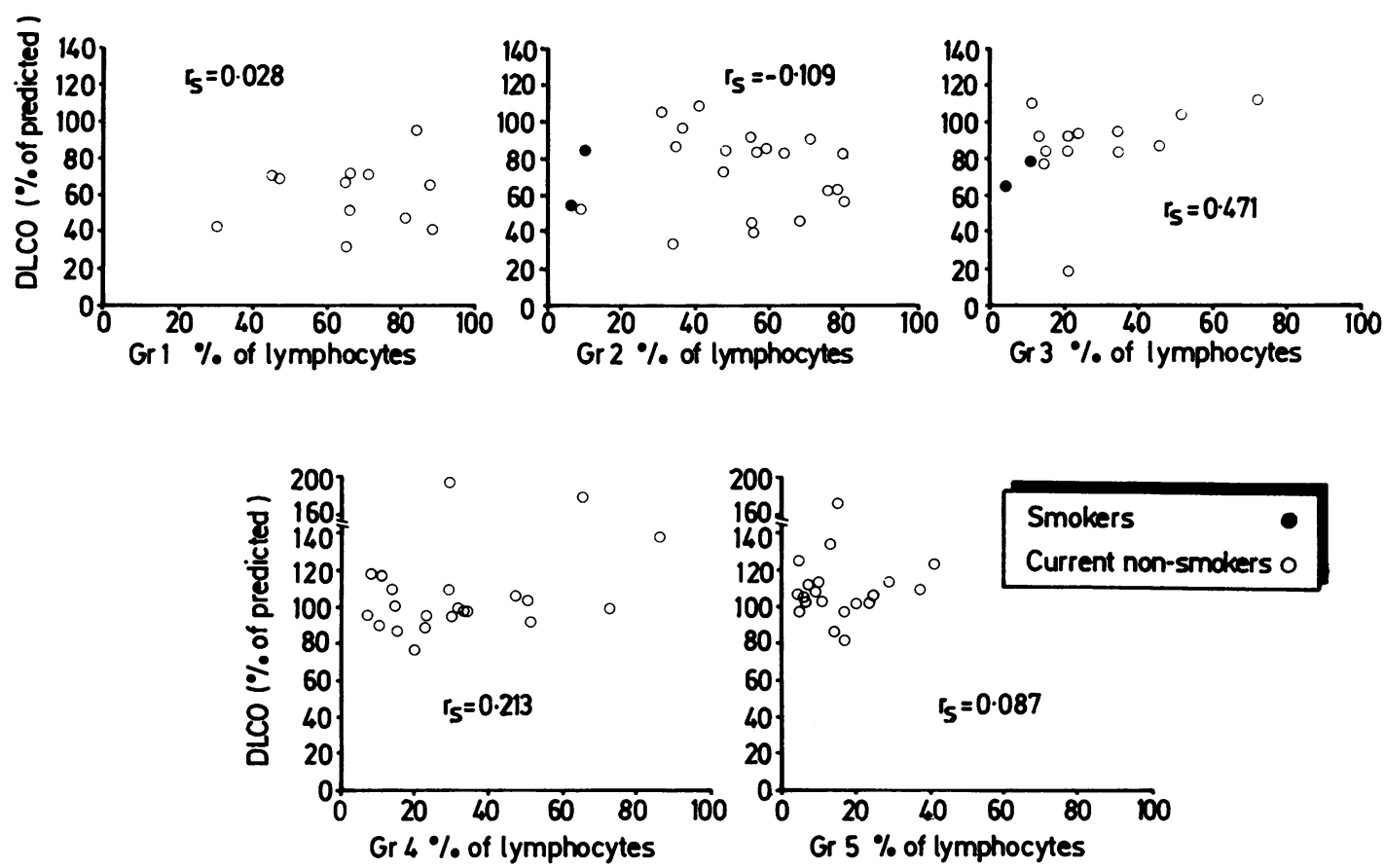

Fig 2 Results of lung diffusion capacity (DLCO) plotted against percentage of lymphocytes in bronchoalveolar lavage fluid for five groups of farmers. See text for definition of each group. There is no significant correlation between DLCO and percentage of lymphocytes.

lymphocytes in BAL of ex-FLD and asymptomatic dairy farmers. For subjects in groups 4 and 5, it may be argued that those with increased lymphocytes have either a subclinical illness or are truly ex-FLD patients who were not diagnosed. FLD could be like many other clinical entities (coccidiodomycosis, tuberculosis), where the vast majority of infections remain subclinical. It is also conceivable that many farmers who present with mild attacks of FLD are labelled as having a respiratory infection. This could account for the asymptomatic farmers with increased BAL lymphocytes; these subjects would represent a group of farmers with previous undiagnosed FLD and now similar to diagnosed subjects in group 2. In this setting an increase in BAL lymphocytes could mean FLD present or past, clinical or subclinical, with diagnosed FLD representing only the tip of the iceberg.

The correlation between clinical signs and symptoms and objective evidence such as BAL analysis is difficult to assess. All the subjects in group 1 were clinically ill but we found a wide range of lymphocytes in their BAL and we could see no difference between patients with more lymphocytes and those with less. Most subjects in group 2, who were free of EAA symptoms, had an increase in their BAL lym- phocytes. Also, since the percentage of lymphocytes in BAL does not mean that there is acute disease, and is not correlated with the degree of functional impairment in most instances (one of the two statistically significant correlations was actually positive), we believe that BAL lymphocytosis has limited value in assessing the severity of EAA. We do not know if the percentage of BAL lymphocytes has a predictive role in FLD as, for example, in sarcoidosis. ${ }^{5}$ Long term follow up and repeated evaluations are needed to see if subjects with a large percentage of lymphocytes have a prognosis different from those with fewer lymphocytes.

We thank Diane Gignac, Monique Lacombe, Lise Petitclerc, Aline Huard, and Clément Blanchet for their technical help.

This study was supported by the Medical Research Council of Canada (MRC 7292), l'Association Pulmonaire du Québec, and La Fondation J D Bégin de l'Université Laval.

YC is a Scholar Fonds de Recherche en Santé du Québec (FRSQ). 


\section{References}

${ }^{1}$ Crystal RG, Roberts WC, Hunninghake GW, Gadek JE, Fulmer JD, Line BR. Pulmonary sarcoidosis: a disease characterized and perpetuated by activated lung T-lymphocytes. Ann Intern Med 1981;94:73-94.

${ }^{2}$ Reynolds HY, Fulmer JD, Kazmierowski JA, Roberts WC, Frank MM, Crystal RG. Analysis of cellular and protein content of bronchoalveolar lavage fluid from patients with idiopathic pulmonary fibrosis and chronic hypersensitivity pneumonitis. J Clin Invest 1977;59:165-75.

${ }^{3}$ Voisin C, Tonnel AB, Lahoute C, Robin H, Lebas J, Aerts C. Bird fancier's lung: studies of broncho-alveolar lavage and correlation with inhalation provocation tests. Lung 1981;159:17-22.

${ }^{4}$ Crystal RG, Gadek JE, Ferrans VJ, Fulmer JD, Line BR, Hunninghake GW. Interstitial lung disease: current concepts of pathogenesis, staging and therapy. Am J Med 1981;70:542-68.

${ }^{5}$ Keogh BA, Crystal RG. Alveolitis: the key to the interstitial lung disorders. Thorax 1982;37:1-10.

${ }^{6}$ Hunninghake GW, Gadek JE, Kawanami O, Ferrans VJ, Crystal RG. Inflammatory and immune processes in the human lung in health and disease: evaluation by bronchoalveolar lavage. $\mathbf{A m}$ J Pathol 1979;97:149-206.

${ }^{7}$ Valenti S, Scordamaglia A, Crimi P, Mereu C. Bronchoalveolar lavage and transbronchial lung biopsy in sarcoidosis and extrinsic allergic alveolitis. Eur J Respir Dis 1982;63:564-9.

${ }^{8}$ Voisin C, Tonnel AB, Aerts C, Lafitte JJ, Ramon P. Les popu- lations cellulaires des espaces aériens broncho-alvéolaires dans la sarcoîdose, les alvéolites allergiques extrinsèques et les cancers bronchiques. La Nouvelle Presse Médicale 1977;6:2685.

${ }^{9}$ Solal-Céligny $\mathrm{Ph}$, Laviolette $\mathrm{M}$, Hébert J, Cormier Y. Immune reactions in the lungs of asymptomatic dairy farmers. Am Rev Respir Dis 1982;126:964-7.

${ }^{10}$ Leblanc P, Bélanger J, Laviolette M, Cormier Y. Relationship between contact, alveolitis and clinical status in farmer's lung. Arch Intern Med (in press).

${ }^{11}$ Ouchterlony O. Diffusion-in-gel method for immunological analysis. In: P Kallos, ed. Progress in allergy. Basel and New York: Karger, 1958;1-78.

${ }^{12}$ Chemlik F, Dolico G, Reed CE, Dickie H. Farmer's lung. J Allergy Clin Immunol 1975;54:180-8.

${ }^{13}$ Cormier Y, Bélanger J, Durand P. Factors affecting the development or serum precipitins to farmer's lung antigen in Quebec dairy farmers. Thorax 1985;40:138-42.

${ }^{14}$ Laviolette $M$. Variation of lymphocyte percentage in bronchoalveolar lavage (BAL) of normal volunteers (abstract). Chest 1984;86:299.

${ }^{15}$ Zar JH. Biostatistical analysis. Englewood Cliffs, NJ: Prentice Hall, 1984.

${ }^{16}$ Salvaggio JE, Kar RM. Hypersensitivity pneumonitis: state of the art. Chest 1979;75:270-4.

${ }^{17}$ Edwards JH, Baker JT, Davis BH. Precipitin test-negative farmer's lung activation of the alternative pathway of complement by mouldy hay dusts. Clin Allergy 1974;4:379-88.

\section{Destruction of manuscripts}

From 1 July 1985 articles submitted for publication will not be returned. Authors whose papers are rejected will be advised of the decision and the manuscripts will be kept under security for three months to deal with any inquiries and then destroyed. 